\title{
Apoptosis is induced by shikonin through the mitochondrial signaling pathway
}

\author{
XUXIA TANG ${ }^{1}$, CHEN ZHANG $^{1}$, JIONGZHOU WEI ${ }^{1}$, YUTING FANG $^{1}$, RONGXIANG ZHAO ${ }^{1}$ and JIANXIN YU ${ }^{2}$ \\ ${ }^{1}$ Department of Otolaryngology, The First Affiliated Hospital of Zhejiang Traditional Chinese Medical University; \\ ${ }^{2}$ Department of Plastic Surgery, The Second Affiliated Hospital of Zhejiang University Medical College,
} Hangzhou, Zhejiang 310000, P.R. China

Received November 19, 2014; Accepted November 16, 2015

DOI: $10.3892 / \mathrm{mmr} .2016 .4967$

\begin{abstract}
The aim of the present study was to investigate the effects of shikonin (SHI) on the induction of apoptosis in human TT medullary thyroid carcinoma cells, and to explore the role of mitochondrial signaling in this process. MTT, Annexin V-phycoerythrin/7-aminoactinomycin D staining, electron microscopy and $\mathrm{JC}-1$ probe staining were performed to analyze mitochondrial membrane potential, and western blot analysis was used to examine the activation of the mitochondrial signaling pathway, and the changes in mitochondrial apoptosis pathway-associated protein expression. Following culture for 24-72 h, treatment with various concentrations of SHI inhibited the proliferation of TT cells, in a dose- and time-dependent manner. Transmission electron microscopy demonstrated the presence of typical apoptotic structures, as well as mitochondrial structural changes. The expression levels of apoptosis-associated proteins caspase-9, caspase-3 and poly adenosine triphosphate ribose polymerase increased in a dose-dependent manner following treatment with SHI. In addition, the mitochondrial membrane potential of the experimental group was significantly decreased, and the mitochondrial apoptosis pathway-associated proteins were altered. A possible mechanism underlying SHI-induced apoptosis through the mitochondrial signaling pathway is the regulation of B cell lymphoma 2 (Bcl-2)/Bcl-2-associated protein $\mathrm{X}$ expression levels, resulting in the decrease in mitochondrial membrane potential and the activation of the caspase-9/caspase-3 enzyme-associated reactions.
\end{abstract}

Correspondence to: Professor Jianxin Yu, Department of Plastic Surgery, The Second Affiliated Hospital of Zhejiang University Medical College, 388 Yu Hangtang Road, Hangzhou, Zhejiang 310000, P.R. China

E-mail: jianxinyucn@126.com

Key words: shikonin, medullary thyroid carcinoma, TT cells, mitochondrial signaling pathway, apoptosis

\section{Introduction}

Medullary thyroid cancer (MTC) originates from the thyroid parafollicular cells (also termed C cells), accounting for 5-10\% of all thyroid malignancies (1). MTC is a type of malignant tumor, the prevalence of which is marginally higher among the female population compared with the male population. At present, surgical removal of the tumor remains the preferred method for the treatment of MTC. Unlike differentiated thyroid cancer, treatment with radioiodine has no therapeutic effect on MTC, and the effects of radiotherapy, radionuclide therapy and chemotherapy remain poor. Biological immune treatments, including molecular targeted drugs, cancer vaccines, monoclonal antibodies, and suicide or immune genes have demonstrated therapeutic effects in clinical or pre-clinical trials $(2,3)$. In recent years, natural medicine has had an important role in cancer treatment, and numerous natural monomer compounds, such as paclitaxel and matrine, have been shown to exhibit antitumor effects $(4,5)$, Therefore, investigating novel therapeutic targets for the treatment of MTC is important for the identification of effective drugs.

Lithospermum erythrorhizon is the dry root of the perennial herb Comfrey Arnebia, and has a long medicinal history in China. Studies have demonstrated that shikonin (SHI), the main effective ingredient of L. erythrorhizon exhibits antitumor effects towards HL60 human promyelocytic leukemia cell lines (5), liver cancer (6), prostate cancer (7), colorectal cancer (8), oral squamous cell carcinoma (9), basal cell carcinoma (10) and osteosarcoma (11). SHI effects the metabolism, proliferation, differentiation, signal transduction and gene expression of tumor cells, and inhibits the activity of DNA topoisomerase, oxidative stress, and proteasomes, thereby inhibiting the growth of tumor cells $(12,13)$. SHI has also been demonstrated to increase the sensitivity of tumor cells towards chemotherapeutic drugs, and may therefore serve as an effective chemical sensitizer $(12,13)$. The death of tumor cells is predominantly induced via three mechanisms: Necrosis, apoptosis and autophagy. Previous studies reported that SHI induced tumor cell death through the apoptotic signaling pathway, and may act by inhibiting the activation of nuclear factor (NF)- $\mathrm{B}$ (14); upregulating caspase proteases (15); inhibiting the expression of survivin (16); regulating the mRNA and protein expression of B cell lymphoma 2 (Bcl-2) 
family-associated genes (8), p53 (8), c-myc (7) and Fas (9); and altering the mitochondrial membrane potential (17). Previous studies have also reported that SHI induced cell death through the non-apoptotic pathway (autophagy and necrosis-like programmed cell death) $(14,15)$.

Studies have yet to report SHI-induced cell death of human TT medullary thyroid carcinoma cells or its underlying mechanism. Thus, the present study investigated SHI-induced cell death of TT cells.

\section{Materials and methods}

Materials and apparatus. SHI, bovine serum albumin and lead citrate were obtained from Sigma-Aldrich (St. Louis, MO, USA). RPMI-1640 was obtained from Gibco Life Technologies, (Carlsbad, CA, USA). MTT was obtained from Fuzhou Maixin Biotechnology Development Co., Ltd. (Fuzhou, China). Annexin V-phycoerythrin (PE)/7-aminoactinomycin D (7-AAD) apoptosis detection kit, cell cycle kit and MitoScreen (JC-1) were obtained from BD Biosciences (San Diego, CA, USA). The following primary antibodies: Rabbit monoclonal anti-Bcl-2 (cat. no. 2870), rabbit monoclonal anti-myeloid cell leukemia 1 (Mcl-1) (cat. no. 5453), rabbit monoclonal anti-Bcl-extra large (xL) (cat. no. 2764), rabbit monoclonal anti-Bcl-2-associated X protein (Bax) (cat. no. 5023), rabbit polyclonal anti-Bcl-2 interacting protein (Bid) (human-specific; cat. no. 2002), mouse monoclonal anti- $\beta$-actin (cat. no. 3700), rabbit polyclonal anti-caspase 3 (cat. no. 9662), rabbit polyclonal anti-cleaved caspase 3 (Asp175) (cat. no. 9661), rabbit polyclonal anti-caspase 9 (cat. no. 9502) and rabbit polyclonal anti-cleaved caspase 9 (cat. no. 9501) were obtained from Cell Signaling Technology, Inc. (Danvers, MA, USA). Polyvinylidene difluoride membrane was obtained from EMD Millipore (Billerica, MA, USA). BD FACSCanto ${ }^{\mathrm{TM}}$ flow cytometer was obtained from BD Biosciences Inc.

Cell culture. Human TT medullary thyroid carcinoma cells (Sigma-Aldrich) were cultured in F-12K medium supplemented with $10 \%$ fetal bovine serum (Gibco Life Technologies) in a humidified incubator at $37^{\circ} \mathrm{C}$ in an atmosphere containing $5 \% \mathrm{CO}_{2}$.

MTT assay. The TT cells were seeded into a 96-well culture plate at a density of $8-10 \times 10^{3}$ cells/well, and the supernatant was discarded when the cells became adherent to the wall. A total of $200 \mu \mathrm{l} \mathrm{SHI}$ at various final concentrations $(0.5,1$, $1.5,2,3,4,6$ and $8 \mu \mathrm{g} / \mathrm{ml}$ ) was subsequently added, with five repeated wells per treatment group. A negative control group, consisting only of RPMI-1640 solution, was also established. Each treatment group was set up in three parallel wells, and in the control group an equal volume of complete media was added. Following drug-cultivation for 24, 48 and $72 \mathrm{~h}$, an MTT assay was performed to analyze the impact of SHI on TT cell growth. The absorbance of each well at $570 \mathrm{~nm}$ was measured by iMark microplate absorbance reader (Bio-Rad Laboratories, Inc., Hercules, CA, USA), and the inhibition rates were calculated according to the following equation: Inhibition rate $=1-\left(\mathrm{OD}_{\text {dosing }}-\mathrm{OD}_{\text {blank }}\right) /\left(\mathrm{OD}_{\text {negative }}-\mathrm{OD}_{\text {blank }}\right) \times 100$. Where $\mathrm{OD}$ is the optical density. The experiment was repeated three times.
Flow cytometry. The cells were inoculated in 6-well culture plates at $20-40 \times 10^{4}$ cells/well. When the cells became wall adherent, $2 \mathrm{ml}$ culture medium containing 2 or $4 \mu \mathrm{g} / \mathrm{ml}$ drug was added to each well, and for the control group an equal volume of complete medium was added. The cells were collected after $24 \mathrm{~h}$ culture, and washed twice with phosphate-buffered saline (PBS), then resuspended in $500 \mu \mathrm{l}$ of $1 \mathrm{X}$ binding buffer. A total of $100 \mu \mathrm{l}$ cell suspension was then added into $5 \mu \mathrm{l}$ Annexin V-PE/7-AAD apoptosis detection solution, prior to being mixed and incubated in the dark at room temperature for $15 \mathrm{~min}$. Following the addition of $400 \mu \mathrm{l}$ of $1 \mathrm{X}$ binding buffer, the apoptosis rate was detected using a Guava ${ }^{\circledR}$ EasyCyte $^{\mathrm{TM}}$ Plus flow cytometer (EMD Millipore).

Preparation of transmission electron microscopy (TEM) samples and observation of apoptotic morphology. The cells in the logarithmic growth phase were seeded into the 6-well plates at a density of $1 \times 10^{6}$ cells/well, and the treatment drug was added $24 \mathrm{~h}$ after inoculation. The blank control group (RPMI-1640-treated cells) and the $24 \mathrm{~h}$ treatment groups (2 and $4 \mu \mathrm{g} / \mathrm{ml} \mathrm{SHI-treated} \mathrm{TT} \mathrm{cells)} \mathrm{samples} \mathrm{were}$ prepared and were sectioned using a Reichert ultramicrotome (Reichert-Jung Inc., Vienna, Austria), in order to obtain 70-90 nm sections, which were stained with lead citrate solution and uranyl acetate (Sigma-Aldrich) 50\%-saturated ethanol solution for $15 \mathrm{~min}$, respectively. Samples were then observed using a TEM (JEM-1400 Plus; JEOL USA, Inc., Peabody, MA, USA).

Impact of SHI on mitochondrial membrane potential $(\Delta \Psi m)$. Cell culture was conducted as previously described in the flow cytometry method, and once the cells became wall adherent, they were washed twice with PBS, prior to treatment with 2 and $4 \mu \mathrm{g} / \mathrm{ml} \mathrm{SHI-containing} \mathrm{medium,} \mathrm{and}$ equal volume of complete medium for $16 \mathrm{~h}$ culture. The cells were collected, and a JC-1 probe was added prior to 15 min incubation at room temperature in the dark. The cells were then washed twice with MitoScreen (JC-1) kit, and the $\Delta \Psi \mathrm{m}$ change was detected with a flow cytometer at $490 \mathrm{~nm}$ excitation wavelength, and mitochondrial morphology was observed using TEM.

Western blot analysis. The cell cultures and drug treatments were conducted as previously described in the flow cytometry methods section. The total protein of the 2 and $4 \mu \mathrm{g} / \mathrm{ml}$ SHI-treated groups was extracted, and protein concentration was measured using the DC Protein Assay kit (Bio-Rad Laboratories, Inc.), according to the manufacturer's protocol. The protein samples were subsequently separated by $10 \%$ SDS-PAGE (Bio-Rad Laboratories, Inc.), then transferred onto polyvinylidene fluoride membranes using the wet method. The membranes were then blocked with $3 \%$ bovine serum albumin for $1 \mathrm{~h}$, prior to being incubated with primary antibodies (1:1,000; Cell Signaling Technology, Inc. ) at room temperature for $3 \mathrm{~h}$. The membranes were then washed three times with Tris-buffered saline with Tween ${ }^{\circledR} 20$ (TBST), and incubated with the horseradish peroxidase-labeled secondary antibody at room temperature for $2 \mathrm{~h}$, and washed three times with TBST. The membranes were treated with ECL reagents (GE Healthcare, Milwaukee, WI, USA) prior to analysis. Images of 
Table I. Human TT medullary thyroid carcinoma cell growth inhibition rate following treatment with various concentrations of SHI $(\%)$.

Growth inhibition rate following SHI treatment $(\mu \mathrm{g} / \mathrm{mg})$

\begin{tabular}{lccccc}
\cline { 3 - 6 } Time $(\mathrm{h})$ & Blank control group & 0.5 & 1 & 2 & 4 \\
\hline 24 & - & $11.3 \pm 5.2$ & $18.9 \pm 5.5$ & $29.3 \pm 4.3^{\mathrm{a}}$ & $51.4 \pm 4.1^{\mathrm{a}}$ \\
48 & - & $15.8 \pm 4.7$ & $30.2 \pm 3.1^{\mathrm{a}}$ & $47.2 \pm 5.1^{\mathrm{a}}$ & $62.7 \pm 3.5^{\mathrm{a}}$ \\
72 & - & $28.4 \pm 4.8^{\mathrm{a}}$ & $40.4 \pm 3.6^{\mathrm{a}}$ & $66.0 \pm 2.5^{\mathrm{a}}$ & $84.3 \pm 2.7^{\mathrm{a}}$ \\
\hline
\end{tabular}

${ }^{\mathrm{a}}<0.05$, vs. the blank control group. SHI, shikonin.

Table II. Changes in the $24 \mathrm{~h}$ TT human medullary thyroid carcinoma cell cycle following treatment with various concentrations of SHI.

\begin{tabular}{|c|c|c|c|c|}
\hline Group & $\mathrm{M} 1\left(\mathrm{G}_{0} / \mathrm{G}_{1}\right.$ phase $)$ & M2 (S phase) & $\mathrm{M} 3\left(\mathrm{G}_{2} / \mathrm{M}\right.$ phase $)$ & M4 (sub- $\mathrm{G}_{0}$ phase) \\
\hline Negative group & 68.8 & 5.7 & 25.0 & 0.2 \\
\hline $2 \mu \mathrm{g} / \mathrm{ml}$ & 22.2 & 2.2 & 10.3 & 21.0 \\
\hline $4 \mu \mathrm{g} / \mathrm{ml}$ & 13.3 & 1.3 & 3.0 & 52.3 \\
\hline
\end{tabular}

Changes in TT cell cycle following $24 \mathrm{~h}$ culture with various concentrations of SHI. The percentages of M1, M2 and M3 were not identified to be significantly increased when compared with the negative control group $(\mathrm{P}>0.05)$. SHI, shikonin.

the target protein were captured and the expression levels were quantified using ChemiDoc ${ }^{\mathrm{TM}} \mathrm{XRS}^{+}$system and Image $\mathrm{Lab}^{\mathrm{TM}}$ software (Bio-Rad Laboratories, Inc.). The following protein expression levels were detected in treated cells: Bcl-2, Bax, Bid, Bcl-xL, Mcl-1, cleaved caspase 9, cleaved caspase 3, and cleaved poly (ADP-ribose) polymerase, with $\beta$-actin serving as an internal control.

Statistical analysis. Comparisons between treatment groups were conducted by one-way analysis of variance, Student's t-test and Pearson correlation analysis. When the intergroup analysis showed no homogeneity, a rank sum test was performed. The SPSS 13.0 statistical package (SPSS, Inc., Chicago, IL, USA) was used to analyze the data. $\mathrm{P}<0.05$ was considered to indicate a statistically significant difference.

\section{Results}

Impact of SHI on the proliferation of TT cells. The effect of treatment with SHI on the proliferation of TT cells as determined by the MTT assay demonstrated that various concentrations of SHI affected the proliferation of TT cells after 24-72 h of culture. TT cell proliferation was shown to increase following treatment with SHI in a dose-dependent manner (Table I).

TT cell cycle changes. In the negative control group, flow cytometry demonstrated the absence of a sub-diploid peak (apoptosis peak), which appeared prior to the $G_{0} / G_{1}$ phase, whereas in the $2 \mu \mathrm{g} / \mathrm{ml}$ SHI-treated cells, the sub-diploid peak appeared after $24 \mathrm{~h}$ of culture. The $4 \mu \mathrm{g} / \mathrm{ml}$ SHI-treated cells exhibited a marked pre- $\mathrm{G}_{0} / \mathrm{G}_{1}$ phase sub-diploid peak (Fig. 1).
The following results in the cell cycle were observed following $24 \mathrm{~h}$ of treatment with various concentrations of SHI. The percentages of cells in the M1 $\left(G_{0} / G_{1}\right), M 2(S)$, and M3 phase $\left(\mathrm{G}_{2} / \mathrm{M}\right)$ in the $24 \mathrm{~h}$ treatment groups ( 2 and $4 \mu \mathrm{g} / \mathrm{ml}$ SHI-treated TT cells) showed no significant increase when compared with the negative control group ( $\mathrm{P}>0.05$; Table II), thus the effects of SHI on the percentages of cells in the various stages of the cell cycle were not significant.

TT cell apoptosis. 7-AAD and Annexin V-PE dual-labeling staining was performed to measure apoptosis levels. Compared with the negative control group, the $2 \mu \mathrm{g} / \mathrm{ml} \mathrm{SHI-treated} \mathrm{group}$ exhibited a higher percentage $(8.03 \%)$ of single-positive cells in early apoptosis (Annexin $\mathrm{V}^{-} \mathrm{PE}^{+} / 7-\mathrm{AAD}^{-}$) after $24 \mathrm{~h}$ of treatment, compared with the control group $(0.1 \%)$. The percentage of double positive cells in late apoptosis, namely the secondary necrosis phase (Annexin $\mathrm{V}^{-} \mathrm{PE}^{+} / 7-\mathrm{AAD}^{+}$), increased to $11.33 \%$, compared with the control group $(0.1 \%)$. After $48 \mathrm{~h}$ of treatment, the percentage of single-positive cells in early apoptosis (Annexin $\mathrm{V}^{-} \mathrm{PE}^{+} / 7-\mathrm{AAD}^{-}$) was increased to $24.99 \%$, and that of the cells in late apoptosis (Annexin $\mathrm{V}^{-} \mathrm{PE}^{+} / 7-\mathrm{AAD}^{+}$) was increased to $14.19 \%$, compared with the control. After $72 \mathrm{~h}$ treatment, the double positive cells (late apoptosis) were the predominant cells, and the ratio markedly increased to $68.73 \%$, whereas single-positive cells accounted for only $6.1 \%$. Intergroup comparison revealed that these results were statistically significant $(\mathrm{P}<0.01)$ (Fig. 2).

Apoptotic morphology observation. TEM was used to observe the cell morphology of the control group after $24 \mathrm{~h}$ treatment (Fig. 3A). TEM observation revealed that the apoptotic morphology of the $2 \mu \mathrm{g} / \mathrm{ml}$ SHI-treated group exhibited 

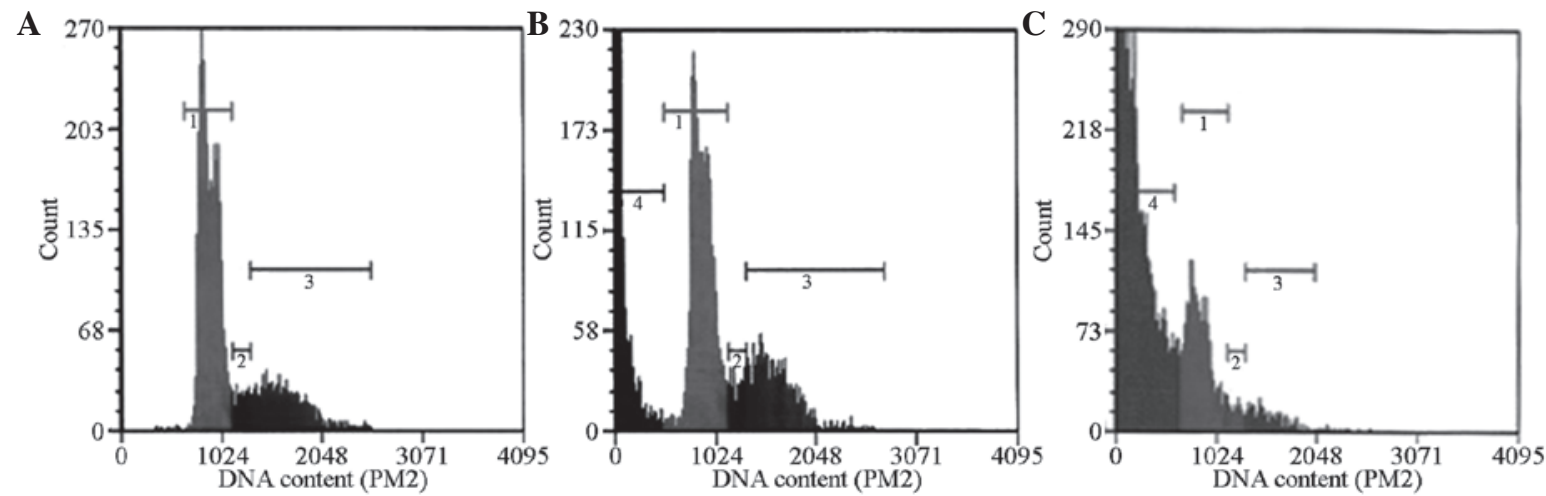

Figure 1. Effect of SHI on TT human medullary thyroid carcinoma cell cycle, as determined by flow cytometric analysis. (A) Negative control, (B) $2 \mu \mathrm{g} / \mathrm{ml}$, and (C) $4 \mu \mathrm{g} / \mathrm{ml}$ SHI-treated groups. SHI, shikonin.
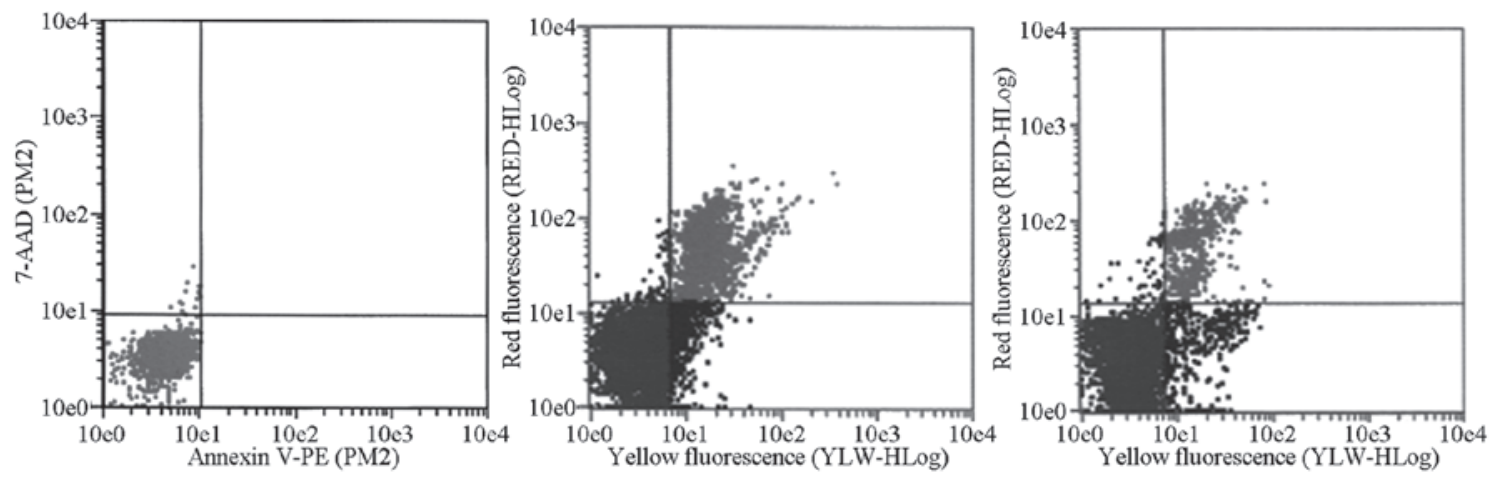

Figure 2. Effect of SHI on TT human medullary thyroid carcinoma cell apoptosis. The TT cell cycle of the experimental groups analyzed by flow cytometry $24 \mathrm{~h}$ following treatment. The 2 and $4 \mu \mathrm{g} / \mathrm{ml} \mathrm{SHI}$-treated groups exhibited marked sub-diploid peaks after $24 \mathrm{~h}$ treatment. The cells treated with $>2 \mu \mathrm{g} / \mathrm{ml}$ SHI exhibited apoptotic peaks (sub-diploid peaks), and the ratio of sub-diploid peaks was positively correlated with concentration, and exhibited statistically significant differences with the control group $(\mathrm{P}<0.01)$, in which no cell cycle blockage was observed. SHI, shikonin.

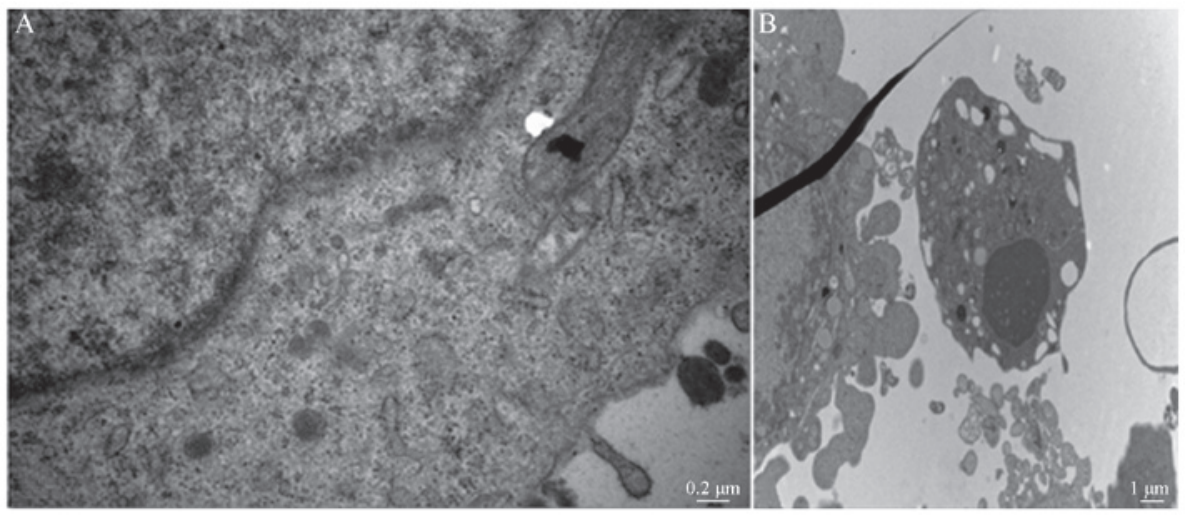

Figure 3. TEM observation of the TT cell-apoptotic morphologies in each group after $24 \mathrm{~h}$ of treatment with SHI. (A) Apoptotic morphology of the negative control group after $24 \mathrm{~h}$ treatment, as determined by TEM. The inner organelles, nucleus, chromosomal morphology and distribution are all normal. (B) Apoptotic morphology of the $2 \mu \mathrm{g} / \mathrm{ml} \mathrm{SHI-treated} \mathrm{groups} \mathrm{after} 24 \mathrm{~h}$ treatment as determined by TEM. The cells are shrunken, and although the membrane structure is intact, the nuclei are condensed or disintegrated and dispersed in the cytoplasm; the chromatin is condensed and marginalized. TEM, transmission electron microscopy; SHI, shikonin.

morphological changes typical of apoptosis after $24 \mathrm{~h}$ treatment (Fig. 3B).

Detection of $\Delta \Psi m$. Detection of the $\Delta \Psi \mathrm{m}$ of the TT cells by flow cytometry revealed that after $4 \mathrm{~h}$ of treatment, the percentage of $2 \mu \mathrm{g} / \mathrm{ml}$ SHI-treated cells with impaired mitochondria increased from 10.1 to $23.4 \%(\mathrm{P}<0.05)$, and that of the $4 \mu \mathrm{g} / \mathrm{ml}$ SHI-treated cells increased to $42.1 \%(\mathrm{P}<0.05)$, compared with the control group. These results suggest that SHI may decrease the $\Delta \Psi \mathrm{m}$ in the TT cells, thereby damaging the mitochondrial membrane (Fig. 4).

TEM was used to observe mitochondrial morphology (Fig. 5), and demonstrated that the mitochondria of the negative control group were stained, with a clearly defined 

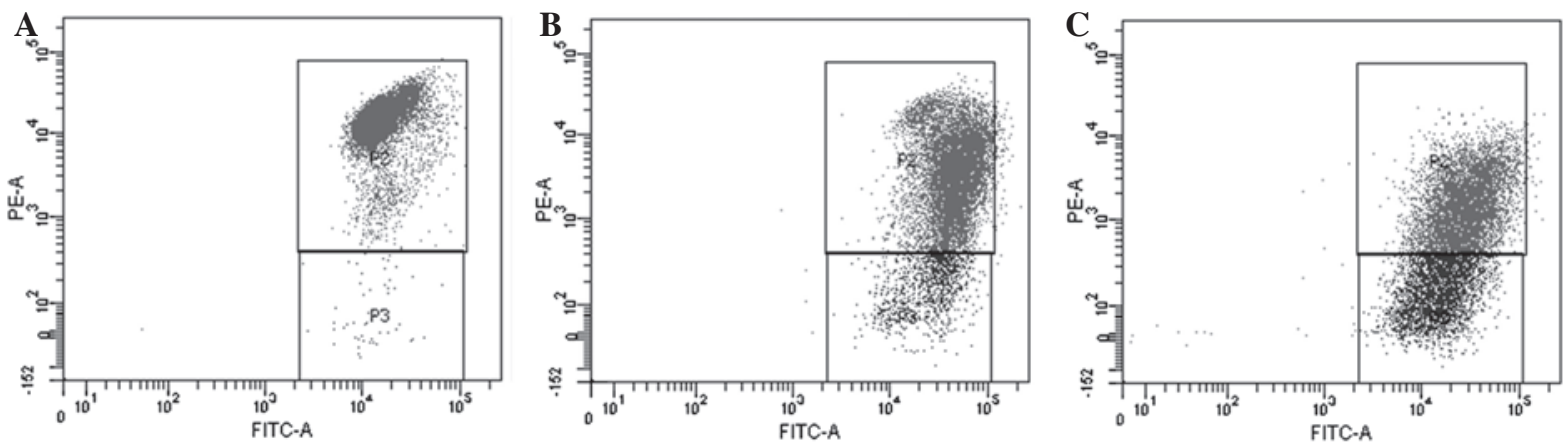

Figure 4. SHI induced the loss of mitochondrial membrane potential $(\Delta \psi \mathrm{m})$. TT cells were treated with the indicated concentration of SHI for $16 \mathrm{~h}$. $\Delta \psi \mathrm{m}$ was determined by flow cytometry using JC-1 Staining. (A) Control; (B) $2 \mu \mathrm{g} / \mathrm{ml} \mathrm{SHI-treated} \mathrm{cells;} \mathrm{(C)} 4 \mu \mathrm{g} / \mathrm{ml}$ SHI-treated cells. SHI, shikonin.

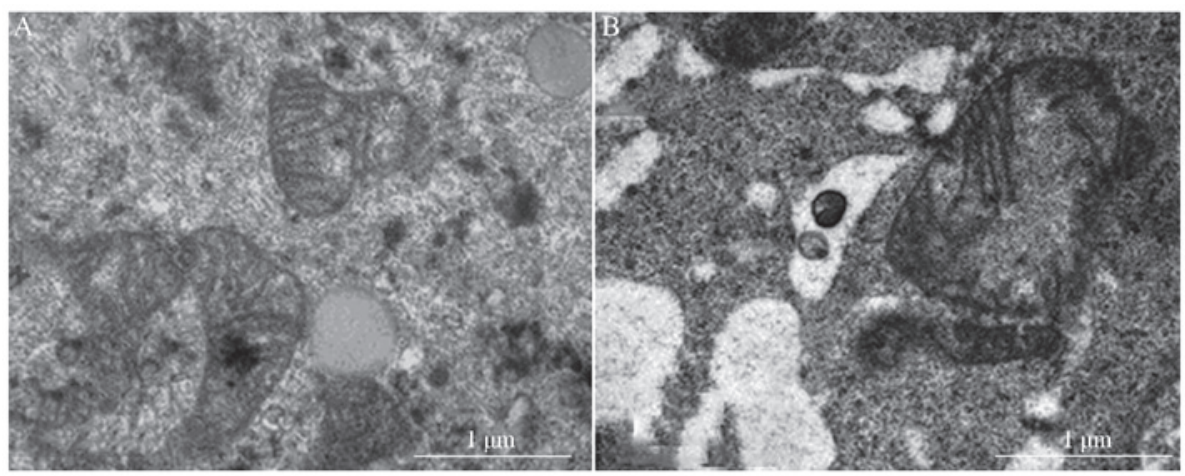

Figure 5. Observation of the mitochondrial morphologies of each group $24 \mathrm{~h}$ following SHI treatment by TEM. (A) Observation of the mitochondrial morphology of TT cells of the negative control group by TEM after $24 \mathrm{~h}$ treatment with SHI. The mitochondria is markedly stained, and the mitochondrial ridge structure is clearly defined. (B) Observation of TT cells of the $2 \mu \mathrm{g} / \mathrm{ml}$ SHI-treated group by TEM after $24 \mathrm{~h}$ of treatment: The mitochondria are abnormally enlarged, and the mitochondrial ridge and membrane are ruptured. SHI, shikonin; TEM, transmission electron microscopy.

A

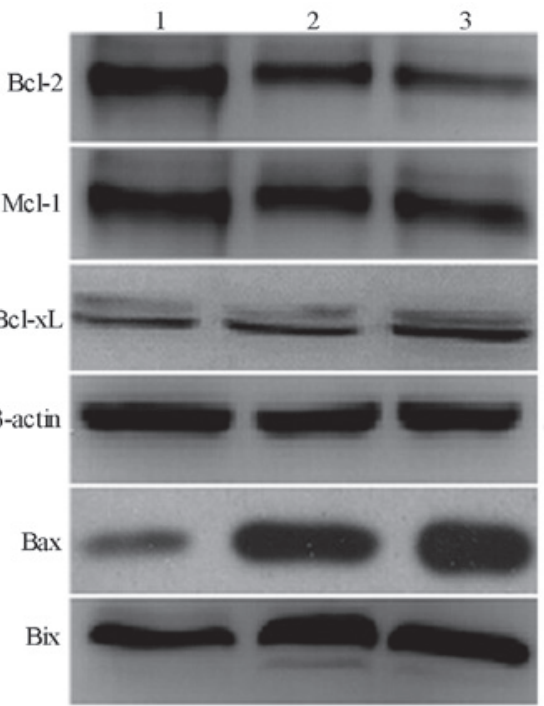

B

ro-caspase

1

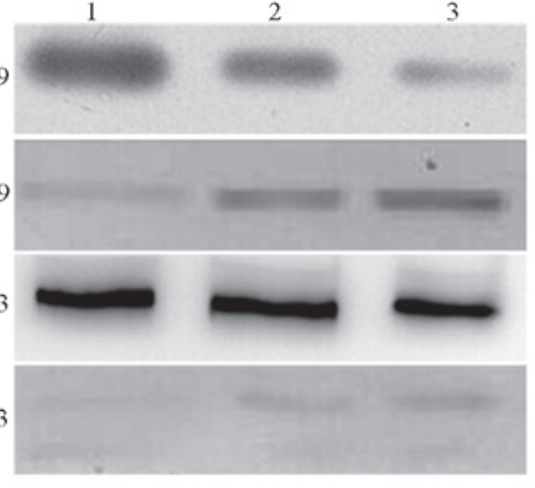

$24 \mathrm{~h}$

Figure 6. Effect of treatment with various concentrations of SHI on the expression levels of Bax, Bcl-xl, Bcl-2, Bik and caspases. (A) Effect of SHI on the expression of Bax, Bcl-xl, Bcl-2 and Bik. (B) Effect of SHI on the expression of caspase-9 and 3. Lane 1, control; lane 2, $2 \mu \mathrm{g} / \mathrm{ml} \mathrm{SHI-treated} \mathrm{cells;} \mathrm{lane} \mathrm{3,} 4 \mu \mathrm{g} / \mathrm{ml}$ SHI-treated cells. SHI, shikonin; Bcl-2, B cell lymphoma 2; Bcl-xL, B cell lymphoma extra large; Bax, Bcl-2-associated protein X; Bid, Bcl-2 interacting protein; Mcl-1, myeloid cell leukemia 1.

mitochondrial ridge structure (Fig. 5A). Conversely, after $24 \mathrm{~h}$ treatment, the $2 \mu \mathrm{g} / \mathrm{ml} \mathrm{SHI-treated} \mathrm{group} \mathrm{exhibited} \mathrm{abnor-}$ mally enlarged mitochondria, and the mitochondrial ridge and membrane were both ruptured (Fig. 5B).
Western blotting determined that SHI alters the expression levels of the Bcl-2 family proteins. Following SHI treatment, western blotting demonstrated that the expression levels of anti-apoptotic proteins Bax and Bid were markedly increased, 
whereas those of Bcl-2, Bcl-xL and Mcl-1 were markedly decreased. This was shown to occur in a dose-dependent manner (Fig. 6A). In addition, following TT cell treatment with 2 and $4 \mu \mathrm{g} / \mathrm{ml} \mathrm{SHI}$, the levels of caspase- 9 and 3 increased in a dose-dependent manner (Fig. 6B).

\section{Discussion}

SHI is the predominant active ingredient of the traditional Chinese medicine Lithospermum erythrorhizon. Its antitumor effects were first reported in 1977 by Sankawa et al (18), who demonstrated that treatment with 5-10 mg/kg/day SHI was able to effectively inhibit the proliferation of mouse S180 ascites sarcoma cells. Since then, further research has determined that SHI may be used as an anticancer drug with multiple targets, exhibiting its antitumor effects by inducing tumor cell apoptosis, inhibiting cell proliferation, inducing cell differentiation and inhibiting tumor cell metastasis $(8,9)$.

A previous study demonstrated that mitochondria had an important role in the apoptosis of malignant tumor cells (19). Decreased $\Delta \Psi \mathrm{m}$ is an early manifestation of apoptosis, and is followed by mitochondrial structural damage, during which small molecules are released, including cytochrome $c$ and apoptosis-inducing factors, and the caspase- 9 and 3 enzyme-linked reactions are activated (8). An association between SHI-induced TT cell apoptosis and mitochondrial signaling has yet to be reported.

The present study used TEM to observe mitochondria, and demonstrated that following treatment with $2 \mu \mathrm{g} / \mathrm{ml} \mathrm{SHI}$ for $24 \mathrm{~h}$, the mitochondria of the TT cells were abnormally enlarged and swollen, and the mitochondrial ridge and membrane were ruptured. Following $4 \mathrm{~h}$ of treatment with SHI, the $\Delta \Psi \mathrm{m}$ of the TT cells decreased, resulting in damage to the mitochondrial membrane. These results suggested that SHI-induced apoptosis was associated with a decrease in $\Delta \Psi \mathrm{m}$ and changes in mitochondrial morphology.

The induction and regulation of mitochondrial outer membrane permeabilization involved numerous proteins, specifically those belonging to the Bcl-2 family. The pro-apoptotic Bcl-2 family members, Bax and Bak, contributed to the mitochondrial outer membrane permeabilization, thereby causing the activation of caspase-9, whereas the anti-apoptotic Bcl-2 and Bcl-xL proteins exhibited inhibitory effects. During the process of SHI-induced apoptosis, the mitochondrial changes increased in a dose-dependent manner, upregulating the expression of Bax and downregulating the expression of $\mathrm{Bcl}-2$, thereby increasing the $\mathrm{Bax} / \mathrm{Bcl}-2$ ratio. A previous study also revealed that SHI was able to induce the upregulation of Bax and the downregulation of Bcl-2 in other tumor cells (20).

The increased Bax/Bcl-2 ratio indicated that the TT cells underwent apoptosis via the mitochondrial signaling pathway, and as the $\Delta \Psi \mathrm{m}$ was decreased, the apoptotic cascade was activated. These results demonstrated that SHI was able to increase the $\mathrm{Bax} / \mathrm{Bcl}-2$ expression ratio. Therefore, the SHI-induced decrease in $\Delta \Psi \mathrm{m}$ may be viewed as the cause of the change in expression levels of the Bcl-2 family proteins.

Previous studies demonstrated that in numerous cell types, such as human bladder cancer cells and oral squamous cell carcinoma cells, SHI may activate caspase-9 and caspase-3 via the mitochondria-dependent signaling pathway (21-23), thereby demonstrating their roles in the promotion of tumor cell apoptosis. In the present study, western blot analysis demonstrated that the expression levels of caspase- 9 and caspase-3 in the SHI-treated cells were downregulated. These results demonstrated the important role of caspases in the SHI-induced TT apoptosis process. The SHI-induced regulation of TT cell apoptosis was mediated by the mitochondrial signaling pathway.

The results of the western blot analysis demonstrated that the expression levels of caspase-9 and caspase-3 in the SHI-treated cells were downregulated, and RT-qPCR analysis also revealed similar results. These results suggested that the caspases had important roles in SHI-induced apoptosis of TT cells.

In conclusion, SHI induced apoptosis of TT cells through the mitochondrial signaling pathway. This was shown by an increase in the expression levels of Bcl-2 apoptotic precursor proteins Bax and Bid and decreased expression levels of anti-apoptotic proteins $\mathrm{Bcl}-2, \mathrm{Bcl}-\mathrm{xL}$ and $\mathrm{Mcl}-1$, thereby increasing the $\mathrm{Bax} / \mathrm{Bcl}-2$ ratio. This resulted in a decrease in the $\Delta \Psi \mathrm{m}$, activation of caspase- 9 and caspase- 3 , and thus apoptosis.

\section{Acknowledgements}

The present study was supported by the Natural Science Foundation of Zhejiang Province (grant no. LY13H130003).

\section{References}

1. Cohen MS and Moley JF: Surgical treatment of medullary thyroid carcinoma. J Intern Med 253: 616-626, 2003.

2. Minemura K, Takeda T, Nagasawa T, Zhang R, Leopardi R and DeGroot LJ: Cell-specific induction of sensitivity to ganciclovir in medullary thyroid carcinoma cells by adenovirus-mediated gene transfer of herpes simplex virus thymidine kinase. Endocrinology 141: 1814-1822, 2000.

3. Soler MN, Milhaud G, Lekmine F, Treilhou-Lahille F, Klatzmann and Lausson S: Treatment of medullary thyroid carcinoma by combined expression of suicide and interleukin-2 genes. Cancer Immunol Immunother 48: 91-99, 1999.

4. Shi Z, Chen J, Li CY, An N, Wang ZJ, Yang SL, Huang KF and Bao JK: Antitumor effects of concanavalin A and Sophora flavescens Iectin in vitro and in vivo. Acta Pharmcol Sin 35: 248-256, 2014

5. Zhang LH, Wang H, Ma GL, Zhang C, Sun HX, Song CX and Kong DS: Study on antitumor activity of paclitaxel-loaded polymeric micelles. Int J Biomed Eng 37: 12-17, 2014.

6. Hashimoto S, Xu M, Masuda Y, Aiuchi T, Nakajo S, Cao J, MiyakoshiM,IdaY andNakayaK:Beta-hydroxyisovalerylshikonin inhibits the cell growth of various cancer cell lines and induces apoptosis in leukemia HL-60 cells through a mechanism different from those of Fas and etoposide. J Biochem 125: 17-23, 1999.

7. Yang H, Zhou P, Huang H, Chen D, Ma N, Cui QC, Shen S, Dong W, Zhang X, Lian W, et al: Shikonin exerts antitumor activity via proteasome inhibition and cell death induction in vitro and in vivo. Int J Cancer 124: 2450-2459, 2009.

8. Hsu PC, Huang YT, Tsai ML, Wang YJ, Lin JK and Pan MH: Induction of apoptosis by shikonin through coordinative modulation of the Bcl-2 family, p27 and p53, release of cytochrome $c$ and sequential activation of caspases in human colorectal carcinoma cells. J Agric Food Chem 52: 6330-6337, 2004.

9. Nam KN, Son MS, Park JH and Lee EH: Shikonins attenuate microglial inflammatory responses by inhibition of ERK, Akt and NF-kappaB: Neuroprotective implications. Neuropharmacology 55: 819-825, 2008.

10. Min R, Tong J, Wenjun Y, Wenhu D, Xiaojian Z, Jiacai H, Jian Z, Wantao $C$ and Chenping Z: Growth inhibition and induction of apoptosis in human oral squamous cell carcinoma Tca-8113 cell lines by Shikonin was partly through the inactivation of NF-kappaB pathway. Phytother Res 22: 407-415, 2008. 
11. Chang IC, Huang YJ, Chiang TI, Yeh CW and Hsu LS: Shikonin induces apoptosis through reactive oxygen species/extracellular signal-regulated kinase pathway in osteosarcoma cells. Biol Pharm Bull 33: 816-824, 2010.

12. Lu L, Qin A, Huang H, Zhou P, Zhang C, Liu N, Li S, Wen G, Zhang C, Dong W, et al: Shikonin extracted from medicinal Chinese herbs exerts anti-inflammatory effect via proteasome inhibition. Eur J Pharmacol 658: 242-247, 2011.

13. Wiench B, Eichhorn T, Paulsen M and Efferth T: Shikonin directly targets mitochondfia and causes mitochondrial dysfunction in cancer cells. Evid Based Complement Alteruat Med 2012: 726025, 2012.

14. Staniforth V, Wang SY, Shyur LF and Yang NS: Shikonins, phytocompounds from Lithospermum erythrorhizon, inhibit the transcriptional activation of human tumor necrosis factor alpha promoter in vivo. J Biol Chem 279: 5877-5885, 2004.

15. Hu X and Xuan Y: Bypassing cancer drug resistance by activating multiple death pathways-a proposal from the study of circumventing cancer drug resistance by induction of necroptosis. Cancer Lett 259: 127-137, 2008.

16. Xuan Y and Hu X: Naturally-occurring shikonin analogues-a class of necroptotic inducers that circumvent cancer drug resistance. Cancer Lett 274: 233-242, 2009.
17. Villena J, Madrid A, Montenegro I, Werner E, Cuellar M and Espinoza L: Diterpenylhydroquinones from natural ent-labdanes induce apoptosis through decreased mitochondrial membrane potential. Molecules 18: 5348-5359, 2013.

18. Sankawa U, Ebizuka Y, Miyazaki T, Isomura Y and Otsuka H: Antitumor activity of shikonin and its derivatives. Chem Pharm Bull (Tokyo) 25: 2392-2395, 1977.

19. Kleibl Z, Raisová M, Novotný J, Pohlreich P and Matous B: Apoptosis and its importance in the development and therapy of tumors (review). Sb Lek 103: 1-13, 2002 (In Czech).

20. Yingkun N, Lvsong Z and Huimin Y: Shikonin inhibits the proliferation and induces the apoptosis of human HepG2 cells. Can J Physiol Pharmacol 88: 1138-1146, 2010.

21. Wu Z, Wu L, Li L, Tashiro S, Onodera S and Ikejima T: P53-mediated cell cycle arrest and apoptosis induced by shikonin via a caspase-9-dependent mechanism in human malignant melanoma A375-S2 cells. J Pharmacol Sci 94: 166-176, 2004.

22. Thangapazham RL, Singh AK, Seth P, Misra N, Mathad VT, Raj K and Maheshwari RK: Shikonin analogue (SA) 93/637 induces apoptosis by activation of caspase-3 in U937 cells. Front Biosci 13: 561-568, 2008

23. Yeh CC, Kuo HM, Li TM, Lin JP, Yu FS, Lu HF, Chung JG and Yang JS: Shikonin-induced apoptosis involves caspase-3 activity in a human bladder cancer cell line (T24). In Vivo 21: 1011-1019, 2007. 